\title{
Microglial Phenotypes and Functions in Multiple Sclerosis
}

\author{
Elaine O'Loughlin, ${ }^{1}$ Charlotte Madore, ${ }^{1}$ Hans Lassmann, ${ }^{2}$ and Oleg Butovsky ${ }^{1,3}$ \\ ${ }^{1}$ Ann Romney Center for Neurologic Diseases, Department of Neurology, Brigham and Women's \\ Hospital, Harvard Medical School, Boston, Massachusetts 02115 \\ ${ }^{2}$ Center for Brain Research, Medical University of Vienna, A-1090 Vienna, Austria \\ ${ }^{3}$ Evergrande Center for Immunologic Diseases, Brigham and Women's Hospital, Harvard Medical \\ School, Boston, Massachusetts 02115 \\ Correspondence: obutovsky@rics.bwh.harvard.edu
}

\begin{abstract}
Microglia are the resident immune cells that constantly survey the central nervous system. They can adapt to their environment and respond to injury or insult by altering their morphology, phenotype, and functions. It has long been debated whether microglial activation is detrimental or beneficial in multiple sclerosis (MS). Recently, the two opposing yet connected roles of microglial activation have been described with the aid of novel microglial markers, RNA profiling, and in vivo models. In this review, microglial phenotypes and functions in the context of MS will be discussed with evidence from both human pathological studies, in vitro and in vivo models. Microglial functional diversity - phagocytosis, antigen presentation, immunomodulation, support, and repair-will also be examined in detail. In addition, this review discusses the emerging evidence for microglia-related targets as biomarkers and therapeutic targets for MS.
\end{abstract}

M ultiple sclerosis (MS) is a complex inflammatory disease accompanied by demyelination of the central nervous system (CNS) (Compston and Coles 2002). MS was first depicted more than 160 years ago and was originally characterized as an inflammatory process with focal plaques and demyelination in white matter brain regions and also the spinal cord (Symonds 1975; Lassmann et al. 2007). It is considered a multifaceted heterogeneous disease, involving different patterns and mechanisms of tissue injury that are often difficult to treat (Lassmann et al. 2001). The mechanism of MS pathology is elusive, but it is known that it involves complex interactions between systems and cell types, including neurons, glia, and immune cells, finally leading to focal lesions of inflammatory demyelination and diffuse neurodegeneration in the brain and spinal cord (Bruck et al. 1995). Supported by the major animal model of MS, the experimental autoimmune encephalomyelitis (EAE), MS was once traditionally thought of a predominantly $\mathrm{T}$-cell-mediated autoimmune disease. It is now known that microglia, the resident CNS immune cells, are key players in MS disease progression (Jack et al. 2005).

Editors: Howard L. Weiner and Vijay K. Kuchroo

Additional Perspectives on Multiple Sclerosis available at www.perspectivesinmedicine.org

Copyright (C) 2018 Cold Spring Harbor Laboratory Press; all rights reserved; doi: 10.1101/cshperspect.a028993

Cite this article as Cold Spring Harb Perspect Med 2018;8:a028993 
E. O’Loughlin et al.

Microglia, the brain's macrophages, occupy $\sim 10 \%$ of the CNS; they are involved in a wide variety of functions, for example, phagocytosis. They are the resident cells of the innate immune system in the brain (Heneka et al. 2014). Microglia provide the first line of defense against invading pathogens and during inflammation. Their primary role is to maintain cellular, synaptic, and myelin homeostasis during the normal function of the CNS and in response to CNS injury (Benarroch 2013). Under homeostatic conditions, microglia typically are characterized by a ramified morphology and continuously monitor their surrounding environment for signs of infection or homeostasis-perturbing events (Gonzalez et al. 2014). Microglia are weak antigen-presenting cells (APCs) but can rapidly transform to an activated macrophage phenotype in response to a specific stimulus (Kettenmann et al. 2011). They are essential to CNS inflammation, can be activated by signals released by neighboring or recruited cells (Facci et al. 2014), and rapidly migrate to the site of infection or injury. They secrete a variety of cytokines, are capable of phagocytosis, and can recruit peripheral cells to the site of injury (Lampron et al. 2013). Microglia can also serve beneficial functions to the host by promoting the formation of new synapses, which in turn facilitates the differentiation and proliferation of neurons (Block and Hong 2007; Gemma and Bachstetter 2013). Microglia participate in the maintenance of tissue homeostasis and synaptic remodeling, but they also contribute in health and disease to the clearance of cellular debris and damaged cells. Microglia are very diverse and, during the past decade, they have emerged as a key target in neurodegenerative and neuroinflammatory diseases. In the context of MS, microglia phagocytosis is a hallmark of MS lesions; they can mount inflammatory responses that can induce bidirectional feedback between resident and infiltrating peripheral cells, further exacerbating the disease.

This review will focus on the roles of microglia phenotype and function in human MS and experimental models and it will also discuss the emerging evidence for microglia-targeted therapies, using these cells as a biomarker in MS.

\section{MICROGLIA PHENOTYPIC DIVERSITY}

\section{Microglia in Acute and Chronic MS Lesions}

The main pathological hallmark of MS is the presence of focal areas of primary demyelination with partial preservation of axons and reactive astrocytic gliosis (Popescu and Lucchinetti 2012). Active demyelination is associated with inflammation and reactive microgliosis (Lassmann 2014). New focal lesions can appear at any site of the brain and spinal cord, but are more likely to occur at sites of high venous density, reflecting the development of brain inflammatory lesions around veins (Haider et al. 2016). Although MS has been associated with a disease affecting the CNS white matter, recent pathological and imaging studies show that demyelinating lesions are also found in cortical gray matter and deep grey matter nuclei in MS patients (Calabrese et al. 2010). MS lesions evolve differently during acute versus chronic disease stages (Popescu and Lucchinetti 2012). Lesion pathology also differs greatly depending on disease type, for example, active acute lesions are more frequent in acute and relapsing-remitting MS (RRMS). These demyelinating plaques are primarily occupied by infiltrating myeloid cells that are evenly distributed throughout the lesion. Chronic "slowly expanding" lesions are more frequent than active acute plaques in patients with progressive MS (Popescu et al. 2013). They are well-delimitated demyelinated lesions where myeloid cells are present at the lesion perimeter. Inactive chronic lesions are characterized by a loss of myelin, axons, and oligodendrocytes and by the presence of very low numbers of inflammatory cells (Frischer et al. 2009).

Microglia, together with macrophages, are the most abundant immune cells in active MS lesions of the brain and spinal cord (Bogie et al. 2014). Activated microglia are present during early and late MS stages (van der Valk and Amor 2009; Singh et al. 2013). MS studies have shown that active lesions correlate with axonal and oligodendrocyte injury and loss (Trapp et al. 1998; Henderson et al. 2009). There is good agreement that cells with a morphological microglia phenotype (small cells with elongated nuclei and ramified cell processes) domi- 
nate in initial lesion areas of new active MS lesions and at the site of lesion expansion in chronic lesions (Barnett and Prineas 2004; Marik et al. 2007; Zrzavy et al. 2017), whereas cells with a macrophage phenotype populate the lesions after the initial destruction of myelin and the phagocytosis of myelin debris (Bruck et al. 1995). However, microglia can transform into a macrophage phenotype (Kettenmann et al. 2011). Because of the difficulty in distinguishing monocytes and microglia, both morphologically and functionally, the complex roles of microglia versus monocytes in the inflammatory/degenerative cascade in MS have not been fully revealed yet. However, with the advancement of specific markers and identification of molecular signatures of these cells, significant advancements are being made in this field (Butovsky et al. 2014; Rinchai et al. 2016).

TMEM119 is expressed by microglia but not by recruited monocytes in rodent CNS and in the human brain (Butovsky et al. 2014; Bennett et al. 2016; Satoh et al. 2016). The marker TMEM119 was used to differentiate cells derived from the resident microglia pool from recruited macrophages in different stages of MS lesions. In initial stages of new active lesions and at the edge of slowly expanding lesions, the majority of IBA-1-positive myeloid cells expressed TMEM119, whereas the percentage of cells with macrophage phenotypes within established plaques declined with lesion maturation. This suggests that the initial tissue damage in MS lesions is mainly associated with activated microglia, and that these cells after phagocytosis of tissue debris transform into cells with a macrophage phenotype. In addition, however, there is a further recruitment of monocytes into established lesions, which coincides with profound additional recruitment of lymphocytes (Marik et al. 2007; Henderson et al. 2009; Zrzavy et al. 2017).

It is still a controversial matter whether demyelination and tissue damage in active MS lesions is initiated by the adaptive inflammatory response or by activated microglia in the absence of a lymphocyte contribution. Experiments using bone marrow chimeric mice showed that microglia activation precedes the onset of EAE and that microglia depletion or down-regulation of microglial genes results in attenuation of disease severity and demyelination in EAE (Heppner et al. 2005; Ponomarev et al. 2005; Goldmann et al. 2013). These studies indicate that microglia can promote disease progression in EAE and possibly also in MS. In line with this concept, preactive lesions have been described in MS, which are defined by clusters of activated microglia in the white matter of MS patients, which develop without demyelination and peripheral cell infiltration (van Horssen et al. 2012), and thus may represent the early stage of inflammatory lesion (van Noort et al. 2011). However, these "preactive" lesions have been described in progressive MS, are very frequent and widespread, and it is therefore highly unlikely that such lesions develop into classical active MS plaques. In addition, they are poorly defined and may also reflect areas of diffuse microglia activation in the normal-appearing white matter of MS patients as well as areas of secondary Wallerian degeneration or even remyelination.

However, in a detailed study on inflammation in relation to demyelinating activity, it was suggested that initial (so-called prephagocytic) lesions in early MS are associated with microglia activation in the absence of lymphocytic infiltrates (Barnett and Prineas 2004). Subsequent studies by the same group (Henderson et al. 2009) and others (Marik et al. 2007) showed that even within and these lesions $\mathrm{T}$ and $\mathrm{B}$ lymphocytes are present, although their number is much smaller compared with that in later lesion stages. From all these studies, it is clear that active demyelination and neurodegeneration is associated with microglia activation. Whether this microglia activation is the primary trigger of lesion formation, whether they are activated by T lymphocytes or B cells, or they are secondary to tissue injury mediated by soluble factors produced by cells of the adaptive immune system is currently unresolved.

\section{Patterns of Microglia Activation in MS Lesions}

The immune reaction in MS lesions has initially been characterized by showing activated T cells and major histocompatibility complex (MHC) class II microglia and macrophages being pres- 
E. O’Loughlin et al.

ent in MS lesions (Traugott et al. 1983). These data suggest that the microglial cells are of major importance in acting as an APC to T cells in the lesions (Woodroofe et al. 1986; Traugott and Zhirmunskaia 1993). However, knowledge regarding the phenotype and function of these cells is so far limited (Bogie et al. 2014). It has been difficult to identify the phenotypic diversity of microglia in MS lesions, mostly because of an absence of unique markers distinguishing microglia from macrophages. Indeed, microglia and macrophages have been wrongly classified as pro- versus anti-inflammatory cells (Martinez and Gordon 2014; Ransohoff 2016). Until recently, no clearly defined lesion stage-dependent phenotype was identified. Macrophages and microglia were considered to present an intermediate phenotype in human MS lesions (Vogel et al. 2013; Peferoen et al. 2015) with a predominance of proinflammatory phenotypes during the acute or early phase of disease (Gao and Tsirka 2011). Microglia in human CNS tissue express a pattern of G-protein-coupled sphingosine-1-phosphate (S1P) receptors similar to mature dendritic cells (DCs) and macrophages but distinct from that seen in circulating monocytes (Hunter et al. 2016). A variety of receptors are expressed at the cell surface of microglia, including complement receptors, scavenger receptors, Fc receptors, Toll-like receptors (TLRs), TREM2, pyrimidinergic receptor P2Y, mannose receptor, and macrophage antigen complex 2 (Napoli and Neumann 2009; Fu et al. 2014). TREM2 is increased in the cerebrospinal fluid of both progressive and RRMS patients (Ohrfelt et al. 2016).

The discovery of specific markers and identification of molecular signatures of microglia made significant advancements in the field (Hickman et al. 2013; Butovsky et al. 2014). A recent study showed that macrophages and microglia have to be defined according to a combination of their morphological and molecular features (Butovsky et al. 2014; Zrzavy et al. 2017). $\mathrm{P} 2 \mathrm{Y} 12$ is a unique microglia marker, expressed on human microglia in homeostasis (Mildner et al. 2017). Although in humans microglia already have a preactivated phenotype in normal white matter in between the homeostatic and proinflammatory phenotypes, P2Y12 expression is reduced in normal-appearing white matter, distant from focal lesions of MS patients, and totally lost in active lesions but is reexpressed on the few microglia that are left over in inactive lesions (Zrzavy et al. 2017). Similar results have been reported previously, although they were only based on a single MS lesion (Mildner et al. 2017). Microglia and macrophages in initial and early active lesion stages showed a dominant expression of proinflammatory markers involved in phagocytosis (CD68), in antigen presentation (MHC class I and II, CD86), and in the production of reactive oxygen species (ROS) (p22phox). In later stages of active lesions, the cells switched to an intermediate phenotype and coexpressed proinflammatory markers with other antigens associated with M2 activation (CD206 and CD163) (Zrzavy et al. 2017). The activation patterns of microglia and macrophages were qualitatively similar in new demyelinating lesions from early MS and in slowly expanding lesions of progressive MS. In addition, microglia and macrophages in active MS lesions also expressed proteins that are involved in iron metabolism, which was in part associated with profound iron accumulation in these cells, in particular, in brains from patients from the progressive stage of the disease (Hametner et al. 2013; Dal-Bianco et al. 2017).

All of the above-described data indicate a prominent role of microglia and macrophages in the pathogenesis of multiple sclerosis lesions. It should, however, be noted that this reaction pattern of microglia and macrophages is not unique for MS. Essentially similar results have been obtained in the analysis of different stages of stroke lesions. Although, in stroke, these microglia activation patterns are seen in relation to fresh lesions, microglia activation in MS is a chronic process associated with slow expansion of preexisting lesions and diffuse injury of the normal-appearing white and grey matter. What drives the chronic microglia activation in MS is currently unknown.

\section{MICROGLIA IN PRECLINICAL STUDIES}

Most advances in our understanding of microglia function in the normal brain and in disease conditions arise from experimental models. 
They include the analysis of the normal brain and its development of inflammatory, demyelinating, and neurodegenerative conditions. For the topic of this review, experimental models of brain inflammation and/or demyelination are most relevant.

Experimental models of brain inflammation and demyelination include the spectrum of autoimmune encephalomyelitis, as well as toxic or virus-induced demyelinating diseases (Lassmann and Bradl 2017). The most characterized and used experimental models are (1) EAE; (2) viral-induced chronic demyelinating disease such as Theiler's murine encephalomyelitis virus (TMEV) infection; and (3) toxin-induced demyelination, such as cuprizone. These models used in combination and in different rodent strains cover a broad spectrum of the MS phenotype. All of these models, in various ways, have allowed us to understand the role of microglia in MS pathogenesis.

EAE can be induced in all vertebrate species by active sensitization of the animals with brain tissue. All brain antigens, which are able to mount specific T-cell responses, can trigger neuroinflammation. This reaction can be induced by active sensitization as well as by passive transfer of autoreactive $\mathrm{CD} 4^{+} \mathrm{T}$-cell populations. EAE induced by autoreactive $\mathrm{CD}^{+} \mathrm{T}$ cells is characterized by pronounced inflammation, which preferentially affects the spinal cord and can, in some animal strains, lead to a chronic disease with focal lesions of demyelination and axonal degeneration. In contrast to the pathology of MS, which is largely defined by confluent plaques of primary demyelination and axonal preservation, the lesions of acute or chronic Tcell-mediated EAE in most instances show extensive axonal injury and destruction with secondary demyelination.

MS-like primary demyelination has so far only been reproduced in experimental models, which are either mediated by oligodendrocytespecific MHC class I-restricted cytotoxic T cells (Saxena et al. 2008) or which mount an additional demyelinating autoantibody response directed against an antigen expressed on the extracellular surface of myelin or oligodendrocytes (Storch et al. 1998). However, the phenotype of
EAE models is highly variable among different animal species. As an example, EAE induced in nonobese diabetic (NOD) mice occurs on the background of a general innate immunity activation (Mayo et al. 2016) and results in a chronic progressive neurological phenotype with larger and more destructive lesions in the CNS in comparison to that in other more frequently used mouse strains, such as the C57B6 mice. For practical reasons, such as reproducibility, handling of the animals and availability of a large spectrum of gene-modified animals, the vast majority of EAE experiments are performed in mice and induced by autoimmunity against the peptide $_{35-55}$ of myelin oligodendrocyte glycoprotein, despite the fact that other EAE models reflect the specific MS lesions more precisely.

In addition, demyelination induced by $\mathrm{cu}-$ prizone, a toxin that induces oxidative damage and mitochondrial dysfunction with selective damage to oligodendrocytes in the corpus callosum and hippocampus (Praet et al. 2014), and other models of toxic demyelination are particularly useful to study mechanisms of demyelination in the absence of an adaptive immunitydriven inflammatory response or the response of oligodendrocyte progenitor cells (OPCs) in the presence of chronically activated microglia (Skripuletz et al. 2011). Within the focus of this review, in such models, the role of microglia and macrophages, which are activated in the context of demyelination, can be analyzed.

Finally, models of viral-induced demyelination are used to study the spontaneous development of inflammatory demyelination in the CNS in the absence of the active (and artificial) induction of an antigen-specific autoimmune response (Gerhauser et al. 2012). The pathogenesis of these models, however, is highly complex, involving direct viral-induced damage of brain cells or oligodendrocytes, a complex immune response involving MHC class I and II-restricted $\mathrm{T}$ cells, and potentially pathogenic antibodies against viral proteins or even autoantigens. A comparison of results obtained in the various experimental models of inflammation and demyelination provides important insight into the microglia phenotype and function for MS pathology. 
E. O’Loughlin et al.

\section{Microglia Phenotype in Models of Inflammation and Demyelination}

There is a large spectrum of models used today to study microglia phenotype and function in vivo (Ransohoff 2012). EAE studies suggest that the brain and spinal cord function as exclusive microenvironments that act differently in response to infiltrating immune cells, with the spinal cord being the most affected with regard to infiltration, tissue damage, and reactive gliosis. Recruited immune cells infiltrate the lesions, and monocyte infiltrates have been shown to play a critical role in the establishment of EAE that is distinct from microglia (Mildner et al. 2009; Ajami et al. 2011). In EAE, blocking the activity or skewing microglia and recruited macrophages toward anti-inflammatory phenotypes has been shown to ameliorate the disease (Hemmer et al. 2015), thus emphasizing a pivotal role for microglia in EAE pathology.

Experiments using bone marrow chimeric mice showed that microglial activation occurs before the onset of EAE, although this is seen only in animals that have mounted a CNS-specific T-cell autoimmune response and not in animals with massive peripheral immune stimulation by complete Freund's adjuvant alone. Thus, it is likely that this microglia activation occurs as a response to initial $\mathrm{T}$-cell infiltration into the meninges. Microglia depletion or down-regulation of microglial genes results in attenuation of disease severity and demyelination in EAE (Heppner et al. 2005; Ponomarev et al. 2005; Goldmann et al. 2013), suggesting that microglia can promote disease progression in EAE. As the first line of defense in the brain, microglia express a number of different TLRs at their cell surface, which helps them recognize molecular patterns associated with injured cells (Miranda-Hernandez and Baxter 2013). Microglia-expressing TLRs are crucial for defense against invading pathogens or autoimmune cells because of their involvement in phagocytosis and the production of inflammatory mediators (Trudler et al. 2010).

Microglia present different activation states with the stage of the disease, which have originally been divided into pro- and anti-inflamma- tory states. A classically activated, M1-like state (associated with host defense, cytotoxicity, secretion of proinflammatory cytokines, proteases, and ROS and reactive nitrogen [RNI] species) defines proinflammatory, activated microglia that are involved in the development and expansion of lesions (Gao and Tsirka 2011). Activated microglia present cell-surface-expressed molecules such as CD14 and MHC, which allow T cells to recognize and bind to small fragments of pathogens (Block and Hong 2007). Activated amoeboid microglia can induce detrimental cellular damage to the host by releasing a number of inflammatory mediators, including proinflammatory cytokines, ROS, RNI, and various complement proteins (Mayo et al. 2012; Gonzalez et al. 2014; Heneka et al. 2014). In addition, they are characterized by the secretion of proinflammatory cytokines (e.g., tumor necrosis factor $\alpha[$ TNF- $\alpha]$ and interferon $\gamma[$ IFN- $\gamma]$ ) and toxic molecules, which further amplify the initial activation, proliferation, and differentiation of $\mathrm{T}$ cells (Greter et al. 2005; Heppner et al. 2005; McMahon et al. 2005), and they lead to neuronal dysfunction and chronic brain inflammation. Furthermore, activated microglia secrete chemokines of the CXC family (interleukin [IL]-8, CXC-ligand-10) and of the CC family (macrophages inflammatory protein- $1 \mathrm{a} / 1 \mathrm{~b}$, monocyte chemoattractant protein-1, CC-ligand-5), which contribute to the intracerebral recruitment of $\mathrm{T}$ cells, additional macrophages, and DCs, which present antigens.

To dampen neuroinflammation, microglia can also adopt an anti-inflammatory phenotype named "M2-like," characterized by thin cell bodies and branched processes (Gonzalez et al. 2014), and this is associated with increased angiogenic capacity. M2-like activation of microglia leads to the secretion of neurotrophic factors and anti-inflammatory mediators such as nerve growth factor (NGF), brain-derived neurotrophic factor (BDNF), insulin-like growth factor 1 (IGF-1), as well as a variety of anti-inflammatory cytokines (e.g., IL-10 and transforming growth factor $\beta$ [TGF- $\beta]$ ), which help diminish neuronal damage and limit the extent of inflammation, promoting the removal of cellular debris in the brain (Mayo et al. 2012). Altogether, 
these changes in functional polarization may play an important role in the induction of remyelination and repair (Miron and Franklin 2014).

Another important mechanism of neuroinflammation is mediated by microglia-mast cell communication, as evidenced by the presence of numerous contact points between these cell types (Skaper and Facci 2012). Engagement of TLR2 and TLR4 on mast cells help recruit immune cells to the sites of injury by releasing various cytokines (Skaper et al. 2014). In addition, IL-33 secreted from microglia binds to mast cells and induces the secretion of immune modulators, including IL-6, IL-13, and monocyte chemoattractant protein, which in turn help regulate the innate immune response (Skaper and Facci 2012). Although the concept of proversus anti-inflammatory microglia activation in relation to damage and repair in the CNS is simple, attractive, and has merits, recent data show that it is an oversimplification. The respective markers and functional states have been defined originally in in vitro systems, using isolated microglia and stimulating them with defined mixtures of cytokines. This is not fully applicable to a complex in vivo situation, in which the cells are stimulated in the context of other cells and by a broad mixture of different cytokines. It is thus not surprising that, in vivo, the majority of microglia show a multifaceted marker expression and that lesion-activated patterns are less obvious.

It is possible to suggest that microglia phenotype and function are a reflection of the environmental cues with the lesions. The first step appears to be a functional change from a homeostatic to an alerted phenotype, which occurs as a reaction to any type of cell degeneration within the CNS. In a second step, environmental cues drive microglia into specific functional states, responding to inflammation, exposure to exogenous agents (viral, bacterial, or fungal infection), to specific types of tissue injury, as well as to vascular damage or to iron liberation within the tissue. As an example, it has been observed in the model of scrapie that neurodegeneration results in microglia activation involved in phagocytosis and in neuroprotection.
However, when this occurred under systemic or local inflammatory conditions, microglia became further activated into a proinflammatory phenotype, which amplified neurodegeneration, postulating the idea of microglial priming (Perry and Holmes 2014). As the first line of defense in the CNS, microglia during MS express numerous TLRs, which enable them to recognize molecular patterns associated with injured cells (Miranda-Hernandez and Baxter 2013). Microglia-expressing TLRs are crucial against invading pathogens or autoimmune cells because of their involvement in phagocytosis and the production of inflammatory mediators (Trudler et al. 2010).

\section{MICROGLIA IMAGING AS A BIOMARKER}

The use of noninvasive molecular imaging techniques helps in the diagnosis and a better understanding of molecular mechanisms in MS. Magnetic resonance imaging (MRI) has been used for decades in MS research and diagnosis. It has more recently been complemented by the use of ultrasmall iron particles (USPIOs), which are taken up by macrophages in the circulation or by microglia in conditions of blood-brain barrier (BBB) damage and allow tracing of these cells in vivo using iron-sensitive MRI sequences. A recent study by Kirschbaum et al. (2016), using MRI and nanoparticles to determine pathology in EAE, showed that the majority of myeloid effector cells have the ability to phagocytose nanoparticles, including microglia, macrophages, and neutrophils, which is a unique approach to imaging the inflammatory responses in EAE. In addition, they used ferumoxytol (Food and Drug Administration [FDA] approved) iron oxide nanoparticles to show that labeled activated microglia, infiltrating macrophages, and neutrophils can be imaged across disease progression in EAE. Moreover, several studies have indicated that myeloperoxidase (MPO) is a potential biomarker for MS disease progression. MPO is one of the most abundant enzymes secreted by activated inflammatory cells. In EAE, MPO knockout mice display increased disease severity in comparison to wild-type (WT) controls (Brennan et al. 2001). Studies have shown that MPO is 
E. O’Loughlin et al.

also found in active human MS plaques (Nagra et al. 1997; Gray et al. 2008a,b). The MPO-sensing MR imaging agent MPO-Gd can be readily synthesized, showing MPO activity as a potential biomarker for activate inflammation and demyelination (Chen et al. 2006, 2008). MPO could be considered a useful biomarker in MS to evaluate the degree of inflammation and to monitor disease progression and thus may act as therapeutic guide. When USPIOs were applied to MS patients, these studies underlined the importance of macrophages and microglia in MS lesions and showed that new macrophage infiltration into the MS brain even occurs at sites that do not show gadolinium enhancement as a sign for local BBB opening. Furthermore, these studies established in vivo the very low turnover of macrophages in established plaques. However, a pitfall of this imaging is that it does not determine what cell types phagocytose these nanoparticles in the human brain. In addition, considering the role of iron within the lesions as an amplification factor for oxidative damage, there are a number of safety concerns related to the use of USPIOs in patients (Gkagkanasiou et al. 2016).

Another potential biomarker for the analysis of microglia and macrophages in MS lesions is their spontaneous uptake of iron when liberated in the lesions. As mentioned above, iron accumulates in the aging human brain in oligodendrocytes. It is liberated during the stage of lesion activity and taken up by microglia at the lesion edge. In addition, increased vascular permeability within the lesions, possibly associated with small microhemorrhages, increases iron load in the lesions and its uptake in macrophages and less prominently in astrocytes (Hametner et al. 2013). In particular, microglial uptake at the lesion perimeter can be visualized in the form of iron rings. Such iron ring lesions label a subset of slowly expanding lesions in the brain of patients with progressive MS (Pitt et al. 2010) and may turn out in the future to be a paraclinical marker for low-grade lesion activity in patients (Pitt et al. 2010; Dal-Bianco et al. 2017). The caveat with this approach, however, is that such iron accumulation at the lesion edge only occurs in brain regions that show increased iron accumulation in the normal brain, such as the forebrain or brain stem. Its absence does not exclude the presence of active lesions in other brain areas.

Now, positron emission tomography (PET) imaging provides new functional information and molecular details before anatomic changes thus leading to a better understanding and follow-up of the disease progression and potential treatment. Neuroinflammation, occuring in MS, provides changes in proteins that can be targeted and detected for imaging purposes. PET imaging of neuroinflammation in MS was focused on monitoring changes in glucose metabolism in addition of the presence of activated microglia in the lesions (Kiferle et al. 2011). Nowadays, most of the PET tracers to detect microglia activation use the expression of the translocator protein TSPO (Ching et al. 2012; Takano et al. 2013). TSPO is a biomarker for the imaging of microglia activation (Ching et al. 2012). TSPO is expressed in the outer membrane of mitochondria and contributes to cholesterol transport into the organelle. TSPO, by gene expression, is almost totally absent from resident microglia in a healthy CNS but will rapidly increase during neuroinflammation (Ching et al. 2012; Banati et al. 2014). Using the isoquinoline carboxamide derivate PK11195, a nonbenzodiazepine ligand specifically binding to TSPO, microglia activation could be observed, however, in a subset of MS patients (Vas et al. 2008). $\left[{ }^{11} \mathrm{C}\right] \mathrm{PK} 11195$ binding was increased in areas of acute and relapse-associated inflammation (Rissanen et al. 2014). It was also increased in activated microglia, not in the lesion, in central gray matter, which is not considered a site of MS pathology, and also in normal-appearing white matter (Banati et al. 2000; Debruyne et al. 2003). Imaging of microglial activation in MS patients could serve as a biomarker for disease progression (Abourbeh et al. 2012; Airas et al. 2015). However, TSPO just identifies activated microglia, but does not allow conclusions regarding their specific pro- or anti-inflammatory activation state. Its visualization by PET imaging is thus considered a nondiagnostic biomarker for brain injury and of limited value as a specific disease marker or an indicator for a specific disease mechanism (Liu et al. 2014). 
Several advances are currently underway that are using other molecular targets to image activated microglia for PET imaging as a biomarker in MS. For example, in vivo applications have investigated microglia receptors (purinergic receptors $\mathrm{P} 2 \mathrm{X} 7$, cannabinoid receptors, $\alpha 7$ and $\alpha 4 \beta 2$ nicotinic acetylcholine receptors, adenosine $2 \mathrm{~A}$ receptor, folate receptor $\beta$ ) and enzymes (cyclooxygenase, nitric oxide synthase, matrix metalloproteinase, $\beta$-glucuronidase, and enzymes of the kynurenine pathway) that are found to be specific to microglia. This approach may lead to more specific targeting and imaging of microglia in MS (Yiangou et al. 2006, Rissanen et al. 2013).

\section{MICROGLIAL FUNCTIONS}

\section{Reaction to Cell or Tissue Damage and Phagocytosis}

MS could be seen as a neurodegenerative disease in which inflammation occurs as a secondary response, augmenting and modifying progressive stages in MS, and demyelinating lesions correlate with the axonal and oligodendrocyte pathology (Trapp et al. 1998; Henderson et al. 2009). It has been observed in MS and in EAE mouse models (Williams et al. 1994; Ransohoff 2012) that macrophages predominate in demyelinated areas and their numbers correlate to EAE severity and disease progression (Huitinga et al. 1990, 1993; Ferguson et al. 1997; Trapp et al. 1998; Ajami et al. 2011). In vivo, Yamasaki et al. (2014) were the first to provide some potential mechanisms regarding the role of microglia versus recruited monocytes in MS. Indeed, they show that recruited monocytes turning into macrophages within the CNS would be the primary effectors and initiate the demyelination, which happens often at the nodes of Ranvier. Meanwhile, microglia appear less effective at disease onset. The two myeloid cell populations show a distinct expression profile at different stages of the disease. Microglia would likely play a role in phagocytosis at early, and recruited macrophages at late, recovery stages (Yamasaki et al. 2014). Targeting the recruited immune cells that are responsible for myelin degradation would be the ideal candidate in terms of the demyelination process.

TREM2 expression by microglia is known to modulate the inflammatory response by suppression of microglia-mediated cytokine production and secretion, and by regulation of phagocytic pathways that clear neuronal debris (Hsieh et al. 2009; Krasemann et al. 2017). A recent study by Bogie et al. identified a scavenger receptor, collectin placenta 1 (CL-P1), as a novel receptor in the uptake of myelin by microglia (phagocytes). Myelin uptake increases the expression of CL-P1 on the surface of human and mouse macrophages. In addition, they showed that knockdown of CL-P1 inhibits myelin uptake (Bogie et al. 2017b). In addition, the expression of CD169 seems to be a selective marker for early-activated microglia in EAE lesions. Depletion of $\mathrm{CD} 169^{+}$cells using diphtheria toxin receptor (DTR) showed a significant reduction in neuroinflammation and ameliorated disease symptoms in EAE-induced mice (Bogie et al. 2017a).

\section{Antigen Presentation in EAE and MS}

Genetic susceptibility to MS has been linked with changes in the antigen presentation, more specifically with specific MHC class II gene phenotypes (Oksenberg et al. 2001). Antigen presentation in the CNS can be considered at the level of the $\mathrm{BBB}$ and within the CNS parenchyma. Competent antigen presentation is dependent on cells expressing both the requisite MHC and costimulatory molecules. Perivascular macrophages were considered the main APC at the level of the BBB because in both humans and rodents they constitutively express MHC class II (Lassmann et al. 1991; Graeber et al. 1992) and their expression is up-regulated in MS lesions (Bo et al. 1994).

\section{Antigen Presentation In Vivo}

APCs are essential for the pathogenesis of EAE (McMahon et al. 2005). In the various in vivo models as discussed above, the APC ultimately has similar overall roles such as antigen processing, presentation, production of costimulatory 
E. O’Loughlin et al.

molecules, and cytokine secretion, all needed to drive stimulation, proliferation, and differentiation of autoreactive T-cell subsets (Bailey et al. 2007). Microglial cells are considered to be the main APC population in the CNS. As previously discussed, microglia are responsible for myelin debris removal, which can be correlated to antigen presentation and processing to $\mathrm{T}$ cells in EAE (Tompkins et al. 2002). Once activated APCs are recruited, they present myelin antigens associated with MHC class II and express costimulatory molecules (e.g., CD40 and B7 glycoproteins) capable of further activating infiltrating T cells (Sanders and De Keyser 2007). Microglia also regulate T-cell differentiation toward T helper (Th) 1 and Th17 pathogenic subtypes through TNF- $\alpha$ (Gao and Tsirka 2011).

Immune cells, such as $\mathrm{T}$ cells, receiving a primary stimulus, typically need costimulatory molecules to become activated, for example, B7CD28 and/or CD40-CD40 ligand (van Kooten and Banchereau 2000). In the context of CD40CD40L, studies have linked this interaction with T-cell microglia cell APC function in EAE. CD40L is a costimulatory molecule expressed on immune cells, primarily by activated T-cell subsets. The CD40 receptor is expressed by professional and nonprofessional APCs, including microglia. In vivo studies showed that CD40 expression by microglia was responsible for recruitment of encephalitogenic T cells in EAE. However, these parenchymal microglia were characterized as "DC-like" microglia in their surface marker expression, CD11c (Becher et al. 2001; Fischer and Reichmann 2001). A study by Wasser et al. (2016) also showed that activated microglia-expressing CD11c showed RNA-seq profile of activated macrophages and contributed to antigen presentation to cytotoxic $\mathrm{T}$ cells in EAE.

In addition, in EAE, cytokines such as IL-17 and IL-22 are up-regulated on the surface of BBB endothelial cells. Stimulation of these cells induces disturbance of the tight junctions, breakdown of the $\mathrm{BBB}$, and thus infiltration of immune cells, particularly $\mathrm{T}$ cells. This mechanism mediates T-cell infiltration to the CNS. Once activated, $\mathrm{T}$ cells traffic/move into the CNS and become restimulated by APCs (microg- lia) thus leading to further inflammatory cascade and disease progression (Wlodarczyk et al. 2014). Microglia produce an array of inflammatory molecules under certain stimuli, up-regulate CD45, MHC, and costimulatory molecules, as well as type 1 IFN and IL-18 production, which in turn can stimulate the proliferation of Th1 and Th17 subsets (Khorooshi and Owens 2010). Moreover, in vitro and ex vivo studies have shown that IFN- $\gamma$-activated, TMEV-infected microglia have the capacity to present myelin and viral peptides to $\mathrm{CD} 4^{+} \mathrm{T}$ cells, further suggesting microglia capabilities to present antigen to T-cell subsets (Aloisi et al. 1998; Mack et al. 2003). However, several studies support the idea that the inflamed CNS contains APC subpopulations with distinct and possibly complementary capability. The majority of studies indicate microglia being "weak" APCs within this cascade (Mack et al. 2003; Shaked et al. 2004; Almolda et al. 2011). Although it is suggested that microglia are "weak" APCs, it is evident that their activation enhances stimulation of infiltrating immune cells, especially $\mathrm{T}$ cells, thus further exacerbating the disease progression (Goverman 2009).

However, using bone marrow chimeric animals, no differences in EAE incidence and severity was seen after passive transfer of encephalitogenic T cells irrespective of whether antigen recognition took place only on recruited myeloid cells or on these cells together with microglia (Hickey and Kimura 1988; Lassmann et al. 1993). These data show that antigen presentation by microglia is not essential for the induction of T-cell-mediated brain inflammation, but that it may play an augmentative or modulating role.

\section{Antigen Presentation in MS}

Although considered weak APCs, microglia in the white matter have been shown to express MHC class II molecules in human and without apparent CNS pathology (Gehrmann et al. 1993; Ulvestad et al. 1994). The low level of expression of microglia MHC class II has been found to be up-regulated after damage or during immune reactions (Chastain et al. 2011). Activation signals for microglia may come from the periphery 
or may be received from the local environment. Initial and subsequent exacerbations of MS have been linked with systemic viral infections (Talbot et al. 2001). A link with bacterial infections, especially urinary tract infections, a source of endotoxins, has also been suggested (Wolfson and Talbot 2002). MS has also been linked with a number of putative viral (human herpes virus [HHV6]) and bacterial (Chlamydia) CNS infections (Moore and Wolfson 2002; Swanborg et al. 2003). The favored hypothesis in MS is that one or more common (e.g., Epstein-Barr virus [EBV] or HHV6), rather than a unique, infection are likely to contribute to disease development. Low levels of endotoxins or pathogenic ligands presented systemically could play the role of an activating signal, accounting for the increased expression of MHCII on the perivascular macrophages, and then transfer the signal to activate microglia in the parenchyma.

Local environment and recruited cells are likely to activate microglia. These cues belong to either the classical nonself pathogen-associated "stranger" signal proposed by Janeway or to the damage-associated "danger" signal proposed by Matzinger that may include self, or endogenous, ligands. Most of the time, these signals bind to common cell-surface receptors (Seong and Matzinger 2004). Indeed, adjuvant-containing killed bacteria or bacterial products are often necessary for successful vaccination in rodent models of MS (Seong and Matzinger 2004). Animal models of MS commonly require injection of mycobacterium along with the myelin-associated peptide (Miller and Karpus 2007; McCarthy et al. 2012). Successful adoptive transfer models conducted in the absence of adjuvant likely reflect the high number and activation status of the transferred antigen-specific $\mathrm{T}$ cells. This results in the up-regulation of molecules that are necessary for antigen presentation and costimulation needing the recruitment of the adaptive immune system. B7-2 or CD86, costimulatory proteins of $\mathrm{MHC}$ class II, are also expressed at a low level on human microglia (Becher and Antel 1996; Bechmann et al. 2001). Another costimulatory protein B7-1 or CD80 has been shown to be up-regulated in early MS plaques (Windhagen et al. 1995).
The apparent up-regulation of APC-related molecules on human microglia under noninflammatory conditions contrasts to most observations made in rodents (Ford et al. 1995), and raises the issue as to whether this reflects intrinsic properties of the human microglia or differences in environmental signals compared with experimental animals raised in "clean" conditions. In this regard, Goverman et al. (1993) found that mice transgenic for a $\mathrm{T}$-cell receptor (TCR) recognizing an encephalitogenic peptide (myelin basic protein) developed spontaneous encephalomyelitis only when kept in a nonsterile environment. We speculate that basal activation of microglia and up-regulation of $\mathrm{MHC}$ expression within the CNS may predispose humans to diseases such as MS.

\section{Microglia-Effects on Oligodendrocytes}

Microglia can produce numerous noxious proinflammatory molecules may induce bystander effects to neighboring glial cells and neurons. In such inflammatory environments, such as MS and EAE, oligodendrocytes are particularly susceptible to microglia-derived factors because of their high metabolic activity and energy demands. For example, in vitro, microglia treated with the bacterial mimetic lipopolysaccharide (LPS), inhibits OPC proliferation and induces OPC cell death. Studies have revealed that stressed oligodendrocytes activate microglia (Peferoen et al. 2014). Moreover, mice lacking proapoptotic genes, or overexpression of antiapoptotic molecules selectively in oligodendrocytes, are resistant to EAE and do not show inflammation-associated demyelination (Hisahara et al. 2000). In scenarios of stress or damage, oligodendrocytes are known to produce mediators that may modulate microglial activation. Oligodendrocyte expression of chemokines CXCL10, CCL2, and CCL3 may suggest that oligodendrocytes actively secrete these molecules to recruit microglial cells to the site of injury/ damage (Balabanov et al. 2007). Once microglia are activated in EAE, they can damage other CNS cells, in particular, oligodendrocytes and neurons (Butovsky et al. 2006; Peferoen et al. 2014). They contain myelin and axonal debris, present 
E. O’Loughlin et al.

with higher expression of MHC class I and II and costimulatory molecules, and secrete different inflammatory and neurotoxic mediators in lesions (Boven et al. 2006; Butovsky et al. 2006; Huizinga et al. 2012; Vogel et al. 2013).

\section{Microglia Immunomodulatory Role}

Several in vivo models mimicking neuroinflammation and neurodegeneration attempt to diminish the CNS damage by modulating microglia inflammatory responses. In the CNS, microglia phenotype and "activation state" can have direct or indirect effects on other cells of the CNS such as neurons, oligodendrocytes, and astrocytes. The importance of microglia in immune modulation was shown by microglial expression of the fractalkine receptor (Cardona et al. 2006). In the CNS, microglia are the only cells to express the fractalkine receptor (CX3CR1), and deficiency of this receptor was shown to induce in vivo neurotoxicity. For example, CX3CR1 knockout mice treated with the bacterial mimetic, LPS, displayed cell-autonomous microglial neurotoxicity. Moreover, in models for Parkinson's and amyotrophic lateral sclerosis (ALS), mice lacking the fractalkine receptor showed significant neuronal loss, showing the potential for microglial neuroprotection via the CX3CR1 receptor (Cardona et al. 2006). More recently, in relation to astrocyte toxicity, the Barres group showed that activated microglia induce reactive astrocytes in states of CNS disease and injury, thus worsening the inflammatory cascade in the CNS (Liddelow et al. 2017).

\section{Cytotoxicity-Oxidative Activation}

Oxidative burst activation of microglia is a characteristic pattern in human inflammatory and neurodegenerative diseases of the CNS. This is reflected by the expression of NADPH oxidase (Haider et al. 2011), MPO (Gray et al. 2008a), and, to a lesser degree, of inducible nitric oxide synthase (iNOS). Oxidative activation in microglia is associated with oxidative injury in lesions with active demyelination or neurodegeneration. Because mitochondria are particularly vulnerable to acute or chronic oxidative injury, it is not surprising to see prominent mitochondrial damage and dysfunction in the multiple sclerosis brain and lesions, which may result in functional disturbances caused by energy deficiency, functional disturbance of the proteins of the respiratory chain (Mahad et al. 2008), and gene deletions of mitochondrially encoded DNA (Campbell et al. 2011). Microglia activation with subsequent oxidative damage is also seen in experimental rodent models (Nikic et al. 2011), but extensive chronic oxidative damage with massive mitochondrial injury and gene deletion, as seen typically in MS lesions, is lacking in rodent models of inflammation and/or demyelination so far (Schuh et al. 2014). Thus, oxidative injury in MS appears to be driven in a self-amplifying vicious cycle of microglia activation-induced oxidative stress and mitochondrial injury and further amplified by age-related iron accumulation in the human brain and its release in the lesions (Mahad et al. 2015).

\section{Reaction to Infectious Agents (Virus, Bacteria, Fungi)}

As mentioned above, microglia express pattern recognition receptors (PRRs), which allow them to sense the presence of infectious bacteria or fungi that have entered the brain compartment. Thus, bacterial CNS invasion, for instance, in the course of a bacterial meningitis, not only activates resident and recruited meningeal macrophages but also the microglia population in the adjacent grey and white matter (Barichello et al. 2016). Activation of microglia in this condition is associated with profound neurodegeneration, in particular in the cortex and hippocampus (Nau and Bruck, 2002). Because similar microglia activation is achieved by the interaction with danger-associated molecular patterns (DAMPS), these processes are amplified by the tissue damage itself (Barichello et al. 2016).

A different pattern of activation has been described in the course of viral infections. In this case, intracellular and extacellular liberation of DNA and RNA may induce macrophage and possibly microglia activation, either through vesicular TLRs (TLR7 and 9) or intracellular pathways of RNA recognition involving mitochon- 
dria (Goldmann et al. 2015). Although they signal through different pathways, they both induce a pronounced type 1 IFN response, which primarily functions to suppress virus infection, but when overexaggerated may by itself induce cell damage in the brain (Rice et al. 2012; Baruch et al. 2014). Interestingly, this pathway can also be activated by liberation of RNA or DNA into the cytoplasm of damaged cells and in particular by intra- and extracellular release of mitochondrial DNA (West and Shadel 2017).

\section{Iron-Related Microglia Pathology-Microglia Senescence}

Microglia density in the CNS tissue increases with age (Poliani et al. 2015), but a subset of these cells in humans, highly expressing ferritin, shows signs of dystrophy or senescence, characterized by a reduction and beading of cell processes (Lopes et al. 2008). Microglia senescence is particularly prominent in the brain of aging patients with progressive MS and is associated with a prominent loss of microglia and macrophages in inactive lesions in comparison to the normal-appearing white matter (Hametner et al. 2013; Zrzavy et al. 2017). Thus, it has been suggested that microglia senescence is related to the uptake of iron, liberated in active lesions as a consequence of the destruction of iron-containing oligodendrocytes. A similar mechanism may operate to the normal aging brain, which occurs on the background of massive iron accumulation in oligodendrocytes (Hallgren and Sourander 1958) and their partial destruction in the aging process.

Differences in Microglia Activation between the Rodent and Human Brain

A major difference between human and rodent microglia is seen in the normal brain in particular in relation to aging. Although in the normal rodent brain microglia display a homeostatic phenotype, and this is even the case in the aging brain, in humans, microglia are already partially activated and the degree of activation increases with aging. This is reflected by a reduced expression of the homeostatic marker P2RY12 and the expression of markers associated with phagocytic (CD68) and oxidative activation (NADPH oxidase) (Zrzavy et al. 2017). Whether this is because of species differences or a result of environmental factors is currently unclear. In this context, it has to be considered that in contrast to a perfusion fixed animal brain, human autopsy cases are confronted with confounding brain injury at the time of death, including for instance preterminal hypoxia or systemic inflammatory diseases, which is further amplified by age- and disease-related comorbidities and life in a less-controlled environment in comparison to animals housed under specific pathogen-free conditions and standardized diets.

In addition, pronounced differences are seen regarding lesion-associated microglia and macrophage activation between multiple sclerosis and the commonly used EAE models. Studies in bone marrow chimeric animals show that the vast majority of effector cells with EAE lesions come from the pool of recruited macrophages and this is reflected by prominent expression of markers associated with phagocytosis and the production of ROS, which are dominantly seen in macrophages and not in microglia (Schuh et al. 2014). iNOS is highly expressed in recruited macrophages in EAE models, whereas its expression in human MS lesions is more prominently seen in astrocytes compared with macrophages and microglia (Marik et al. 2007; Zrzavy et al. 2017). Although more prominent expression of these molecules is seen in microglia in the model of EAE in NOD mice, these basic differences are even seen in this model (Mayo et al. 2012).

Finally, the human brain accumulates iron with aging (Hametner et al. 2013), which is liberated in actively demyelinating MS lesions and taken up by microglia and macrophages. Iron uptake in microglia and macrophages is associated with proinflammatory activation (Pitt et al. 2010).

\section{TARGETING MICROGLIA AS AN MS TREATMENT}

A proof-of-principle, that inhibition of microglia activation has a beneficial effect on MS, has 
E. O’Loughlin et al.

recently been obtained in a trial using minocycline. This drug, which has been shown to target microglia activation and has beneficial effects in several different experimental models of inflammation and neurodegeneration, reduced the conversion of clinically isolated syndrome (CIS) into definite MS in MS patients and reduced clinically or radiologically identified activity of the disease (Metz et al. 2017).

\section{Fingolimod}

Fingolimod (FYT720) is the first orally available treatment to be approved for relapsing forms of MS. FTY720 is a potent agonist of S1P receptor that regulates immune cell trafficking to the CNS by reducing infiltration. Clinical trials showed that FTY720 reduces brain atrophy and reduces relapse rates (Kappos et al. 2006). Because of its lipophilic nature, FTY720 can cross the $\mathrm{BBB}$ and interact with all CNS cell types. However, the effects of FTY720 on microglia in MS largely remain unclear. Studies have shown that TY720 can suppress microglial production of classical proinflammatory cytokines such as IL-1 $\beta$, TNF- $\alpha$, and IL-6. Moreover, FTY720 has been shown to promote microglial production of BDNF and also glial cell line-derived neurotrophic factor (GDNF), which may suggest a potential neuroprotective role in $\mathrm{mi}-$ croglial functions (Noda et al. 2013). A recent study by Das et al. (2017) showed, via high-resolution RNA-seq, that FTY720 regulates key inflammatory responses in microglial cells, further emphasizing its role in inflammation but not in MS specifically. In vitro and in vivo studies of FTY720 in EAE showed that modulation of the S1P receptors can ameliorate pathology associated with microglial activation. In addition, this leads to the subsequent increase in protein and morphological markers of remyelination (e.g., myelin basic protein) (Miron et al. 2010). FTY720 has beneficial effects in reducing inflammation and inducing remyelination in a concomitant fashion as seen in vitro using organ cerebellar slices (Miron et al. 2008, 2010). Moreover, treatment with FTY720 in EAE dramatically reduces EAE severity and disease progression (Webb et al. 2004). FTY720 can alter myelin gene expression, reduce pathological changes, and, thus, have consequences for MS. In 2007, Foster et al. showed that FTY720 has numerous beneficial effects in EAE, while reducing disease severity, histopathological score, and immune cell infiltration; however, the cellular targets and mechanism of action remains to be debated. We conclude that the preclinical results of FTY720 on microglial cells can be extrapolated to the clinical setting, but more investigations are needed on the specificity of FTY720 microglial effects (Foster et al. 2007).

IFN- $\beta$

IFN- $\beta$ represents the standard treatment for relapsing forms of MS. In EAE studies, exogenous administration of IFN- $\beta$ shows protective effects. IFN- $\beta$ knockout leads to augmented and chronic demylination in EAE, associated with microglia activation and sustained inflammation with concomitant cytokine production, tissue damage, and chronic neurological deficits (Teige et al. 2003). Moreover, this effect was attributed to myeloid cells as shown by specific deletion of type 1 IFN receptor in myeloid cells. The same deletion in $\mathrm{B}$ or $\mathrm{T}$ cells had no effect on disease severity (Prinz et al. 2008). Further depicting the role of IFN- $\beta$ in microglia, Kocur et al. (2015) used IFN- $\beta$-florescent reporter mice to show that microglia are the major producers of IFN- $\beta$ at the peak stage of EAE and accomplish IFN- $\beta$-induced clearance of myelin debris.

\section{microRNAs (miRNA)-Based miR124}

miRNAs are small noncoding nucleotide RNAs that play key roles in posttranscriptional regulation of gene expression. MiR-124 is one of the most abundant miRNAs in the brain, accounting for more than a quarter of all miRNAs (Krichevsky et al. 2003). An interesting study by Ponomarev et al. (2011) showed that miR-124 was affected in EAE disease progression. In the EAE model, they showed that microglial expression of miR-124 decreased by $\sim 70 \%$ over the course of EAE progression. Overexpression of miR-124 promotes microglial quiescence and suppresses EAE. In addition, administration of 
miR-124 results in diminished macrophage response, reduced activation of autoreactive $\mathrm{T}$ cells, and significant suppression of EAE disease score (Ponomarev et al. 2011). Although all CNS cells, particularly neurons, express miR-124, the question still remains whether specific microglial targeting of miR-124 is clinically relevant as an MS treatment.

\section{Antibodies against Granulocyte Macrophage Colony-Stimulating Factor (GM-CSF)}

GM-CSF is a growth factor first identified as an inducer of granulocyte and macrophage differentiation and proliferation from hematopoietic progenitor cells. Studies suggest that GM-CSF has several proinflammatory functions and also plays critical roles in autoimmune and inflammatory diseases. In vivo, GM-CSF was shown to be essential in the induction of encephalitogenic $\mathrm{CD}^{+} \mathrm{T}$ cells in EAE (El-Behi et al. 2011). In addition, administration of recombinant GM-CSF significantly exacerbated EAE disease, thus making this factor an attractive target in MS (McQualter et al. 2001). However, it is currently unresolved which cells in the inflammatory environment of EAE and MS produce GM-CSF and contribute to the autoimmunity cascade. Croxford et al. (2015) showed that GM-CSF drives the inflammation of $\mathrm{Ly} 6 \mathrm{C}^{\mathrm{High}}$ monocytes, showing that neutrophils, conventional DCs (cDCs), and microglia do not require GM-CSF for EAE disease development. As with many other therapeutic molecules, the full mechanism of action is yet to be resolved. There are several ongoing and completed clinical trials targeting GM-CSF or its receptor for the treatment of autoimmune diseases. For example, MOR103, a GM-CSF antibody, has shown to be beneficial in patients with RRMS and secondary-progressive MS (SPMS) (Constantinescu et al. 2015).

\section{Laquinimod}

Laquinimod is an orally available compound to treat RRMS that has shown to be successful in phase II/III clinical trials. However, as with many compounds, the exact mode of action re- mains unclear. In vivo studies have shown that laquinimod reduces leukocyte infiltration to the CNS, induces a shift from cytotoxic Th1 to Th2/ 3 , and dampens the Th17 responses in the EAE model (Yang et al. 2004; Wegner et al. 2010). In the context of microglia, laquinimod is a novel inhibitor of microglial activation that decreases microglial-induced neuronal cell death in vitro and axonal degeneration/loss in vivo (Mishra et al. 2014). In EAE, axonal injury is often correlated with the accumulation of microglia/macrophages in the spinal cord. Mice treated with laquinimod before onset of clinical signs had marked reduction in microglia/macrophage density and axonal injury/loss. In addition, treatment with laquinimod halted disease progression and production of inducible nitric oxide, thus attenuating the neurodegeneration associated with EAE (Mishra et al. 2014).

\section{CONCLUDING REMARKS}

This review aimed to discuss the diversity of microglial functions and phenotypes in preclinical models and recent findings relevant to MS. Our knowledge of microglia is slowly unraveling with the aid of new technologies and development of specific antibodies and markers to distinguish them from their peripheral and central immune counterparts. Thus, these advances open avenues for potential microglial-related targets in MS aimed to manipulate and restore microglial functions. In addition, imaging tools may be developed to use microglia as a biomarker to monitor disease progression in MS.

\section{REFERENCES}

Abourbeh G, Theze B, Maroy R, Dubois A, Brulon V, Fontyn Y, Dolle F, Tavitian B, Boisgard R. 2012. Imaging microglial/macrophage activation in spinal cords of experimental autoimmune encephalomyelitis rats by positron emission tomography using the mitochondrial $18 \mathrm{kDa}$ translocator protein radioligand $\left[{ }^{18} \mathrm{~F}\right] \mathrm{DPA}-714$. J Neurosci 32: 5728-5736.

Airas L, Rissanen E, Rinne JO. 2015. Imaging neuroinflammation in multiple sclerosis using TSPO-PET. Clin Transl Imaging 3: 461-473.

Ajami B, Bennett JL, Krieger C, McNagny KM, Rossi FM. 2011. Infiltrating monocytes trigger EAE progression, but 
E. O’Loughlin et al.

do not contribute to the resident microglia pool. Nat Neurosci 14: 1142-1149.

Almolda B, Gonzalez B, Castellano B. 2011. Antigen presentation in EAE: Role of microglia, macrophages and dendritic cells. Front Biosci (Landmark Ed) 16: 1157-1171.

Aloisi F, Ria F, Penna G, Adorini L. 1998. Microglia are more efficient than astrocytes in antigen processing and in Th1 but not Th2 cell activation. J Immunol 160: 4671-4680.

Bailey SL, Schreiner B, McMahon EJ, Miller SD. 2007. CNS myeloid DCs presenting endogenous myelin peptides "preferentially" polarize $\mathrm{CD}^{+} \mathrm{T}_{\mathrm{H}^{-}} 17$ cells in relapsing EAE. Nat Immunol 8: 172-180.

Balabanov R, Strand K, Goswami R, McMahon E, Begolka W, Miller SD, Popko B. 2007. Interferon- $\gamma$-oligodendrocyte interactions in the regulation of experimental autoimmune encephalomyelitis. J Neurosci 27: 2013-2024.

Banati RB, Newcombe J, Gunn RN, Cagnin A, Turkheimer F, Heppner F, Price G, Wegner F, Giovannoni G, Miller DH, et al. 2000. The peripheral benzodiazepine binding site in the brain in multiple sclerosis: Quantitative in vivo imaging of microglia as a measure of disease activity. Brain 123: 2321-2337.

Banati RB, Middleton RJ, Chan R, Hatty CR, Kam WW, Quin C, Graeber MB, Parmar A, Zahra D, Callaghan P, et al. 2014. Positron emission tomography and functional characterization of a complete PBR/TSPO knockout. Nat Commun 5: 5452.

Barichello T, Generoso JS, Simoes LR, Goularte JA, Petronilho F, Saigal P, Badawy M, Quevedo J. 2016. Role of microglial activation in the pathophysiology of bacterial meningitis. Mol Neurobiol 53: 1770-1781.

Barnett MH, Prineas JW. 2004. Relapsing and remitting multiple sclerosis: Pathology of the newly forming lesion. Ann Neurol 55: 458-468.

Baruch K, Deczkowska A, David E, Castellano JM, Miller O, Kertser A, Berkutzki T, Barnett-Itzhaki Z, Bezalel D, Wyss-Coray T, et al. 2014. Aging-induced type I interferon response at the choroid plexus negatively affects brain function. Science 346: 89-93.

Becher B, Antel JP. 1996. Comparison of phenotypic and functional properties of immediately ex vivo and cultured human adult microglia. Glia 18: 1-10.

Becher B, Durell BG, Miga AV, Hickey WF, Noelle RJ. 2001. The clinical course of experimental autoimmune encephalomyelitis and inflammation is controlled by the expression of CD40 within the central nervous system. J Exp Med 193: 967-974.

Bechmann I, Peter S, Beyer M, Gimsa U, Nitsch R. 2001. Presence of B7-2 (CD86) and lack of B7-1 (CD80) on myelin phagocytosing MHC-II-positive rat microglia is associated with nondestructive immunity in vivo. FASEB J 15: 1086-1088.

Benarroch EE. 2013. Microglia: Multiple roles in surveillance, circuit shaping, and response to injury. Neurology 81: 1079-1088.

Bennett ML, Bennett FC, Liddelow SA, Ajami B, Zamanian JL, Fernhoff NB, Mulinyawe SB, Bohlen CJ, Adil A Tucker A, et al. 2016. New tools for studying microglia in the mouse and human CNS. Proc Natl Acad Sci 113: E1738-E1746.
Block ML, Hong JS. 2007. Chronic microglial activation and progressive dopaminergic neurotoxicity. Biochem Soc Trans 35: 1127-1132.

Bo L, Mork S, Kong PA, Nyland H, Pardo CA, Trapp BD. 1994. Detection of MHC class II-antigens on macrophages and microglia, but not on astrocytes and endothelia in active multiple sclerosis lesions. J Neuroimmunol 51: 135-146.

Bogie JF, Stinissen P, Hendriks JJ. 2014. Macrophage subsets and microglia in multiple sclerosis. Acta Neuropathol 128: 191-213.

Bogie JF, Boelen E, Louagie E, Delputte P, Elewaut D, van Horssen J, Hendriks JJ, Hellings N. 2017a. CD169 is a marker for highly pathogenic phagocytes in multiple sclerosis. Mult Scler doi: 10.1177/1352458517698759.

Bogie JF, Mailleux J, Wouters E, Jorissen W, Grajchen E, Vanmol J, Wouters K, Hellings N, Van Horsen J, Vanmierlo T, et al. 2017b. Scavenger receptor collectin placenta 1 is a novel receptor involved in the uptake of myelin by phagocytes. Sci Rep 7: 44794.

Boven LA, Van Meurs M, Van Zwam M, Wierenga-Wolf A, Hintzen RQ, Boot RG, Aerts JM, Amor S, Nieuwenhuis EE, Laman JD. 2006. Myelin-laden macrophages are antiinflammatory, consistent with foam cells in multiple sclerosis. Brain 129: 517-526.

Brennan M, Gaur A, Pahuja A, Lusis AJ, Reynolds WF. 2001. Mice lacking myeloperoxidase are more susceptible to experimental autoimmune encephalomyelitis. J Neuroimmunol 112: 97-105.

Bruck W, Porada P, Poser S, Rieckmann P, Hanefeld F, Kretzschmar HA, Lassmann H. 1995. Monocyte/macrophage differentiation in early multiple sclerosis lesions. Ann Neurol 38: 788-796.

Butovsky O, Landa G, Kunis G, Ziv Y, Avidan H, Greenberg N, Schwartz A, Smirnov I, Pollack A, Jung S, et al. 2006. Induction and blockage of oligodendrogenesis by differently activated microglia in an animal model of multiple sclerosis. J Clin Invest 116: 905-915.

Butovsky O, Jedrychowski MP, Moore CS, Cialic R, Lanser AJ, Gabriely G, Koeglsperger T, Dake B, Wu PM, Doykan CE, et al. 2014. Identification of a unique TGF- $\beta$-dependent molecular and functional signature in microglia. Nat Neurosci 17: 131-143.

Calabrese M, Filippi M, Gallo P. 2010. Cortical lesions in multiple sclerosis. Nat Rev Neurol 6: 438-444.

Campbell GR, Ziabreva I, Reeve AK, Krishnan KJ, Reynolds R, Howell O, Lassmann H, Turnbull DM, Mahad DJ. 2011. Mitochondrial DNA deletions and neurodegeneration in multiple sclerosis. Ann Neurol 69: 481-492.

Cardona AE, Pioro EP, Sasse ME, Kostenko V, Cardona SM, Dijkstra IM, Huang D, Kidd G, Dombrowski S, Dutta R, et al. 2006. Control of microglial neurotoxicity by the fractalkine receptor. Nat Neurosci 9: 917-924.

Chastain EM, Duncan DS, Rodgers JM, Miller SD. 2011. The role of antigen presenting cells in multiple sclerosis. Biochim Biophys Acta 1812: 265-274.

Chen JW, Querol Sans M, Bogdanov A Jr, Weissleder R. 2006. Imaging of myeloperoxidase in mice by using novel amplifiable paramagnetic substrates. Radiology 240: 473481. 
Chen JW, Breckwoldt MO, Aikawa E, Chiang G, Weissleder R. 2008. Myeloperoxidase-targeted imaging of active inflammatory lesions in murine experimental autoimmune encephalomyelitis. Brain 131: 1123-1133.

Ching AS, Kuhnast B, Damont A, Roeda D, Tavitian B, Dolle F. 2012. Current paradigm of the $18-\mathrm{kDa}$ translocator protein (TSPO) as a molecular target for PET imaging in neuroinflammation and neurodegenerative diseases. Insights Imaging 3: 111-119.

Compston A, Coles A. 2002. Multiple sclerosis. Lancet 359: 1221-1231.

Constantinescu CS, Asher A, Fryze W, Kozubski W, Wagner F, Aram J, Tanasescu R, Korolkiewicz RP, DirnbergerHertweck M, Steidl S, et al. 2015. Randomized phase $1 \mathrm{~b}$ trial of MOR103, a human antibody to GM-CSF, in multiple sclerosis. Neurol Neuroimmunol Neuroinflamm 2: e117.

Croxford AL, Lanzinger M, Hartmann FJ, Schreiner B, Mair F, Pelczar P, Clausen BE, Jung S, Greter M, Becher B. 2015. The cytokine GM-CSF drives the inflammatory signature of CCR $2^{+}$monocytes and licenses autoimmunity. Immunity 43: 502-514.

Dal-Bianco A, Grabner G, Kronnerwetter C, Weber M, Hoftberger R, Berger T, Auff E, Leutmezer F, Trattnig S, Lassmann H, et al. 2017. Slow expansion of multiple sclerosis iron rim lesions: Pathology and $7 \mathrm{~T}$ magnetic resonance imaging. Acta Neuropathol 133: 25-42.

Das A, Arifuzzaman S, Kim SH, Lee YS, Jung KH, Chai YG. 2017. FTY720 (fingolimod) regulates key target genes essential for inflammation in microglial cells as defined by high-resolution mRNA sequencing. Neuropharmacology 119: 1-14.

Debruyne JC, Versijpt J, Van Laere KJ, De Vos F, Keppens J, Strijckmans K, Achten E, Slegers G, Dierckx RA, Korf J, et al. 2003. PET visualization of microglia in multiple sclerosis patients using $\left[{ }^{11} \mathrm{C}\right] \mathrm{PK} 11195$. Eur J Neurol 10: 257 264.

El-Behi M, Ciric B, Dai H, Yan Y, Cullimore M, Safavi F, Zhang GX, Dittel BN, Rostami A. 2011. The encephalitogenicity of $\mathrm{T}_{\mathrm{H}} 17$ cells is dependent on IL-1- and IL-23induced production of the cytokine GM-CSF. Nat Immunol 12: 568-575.

Facci L, Barbierato M, Marinelli C, Argentini C, Skaper SD, Giusti P. 2014. Toll-like receptors $2,-3$ and -4 prime microglia but not astrocytes across central nervous system regions for ATP-dependent interleukin-1 $\beta$ release. Sci Rep 4: 6824.

Ferguson B, Matyszak MK, Esiri MM, Perry VH. 1997. Axonal damage in acute multiple sclerosis lesions. Brain: $J$ Neurol 120(Pt 3): 393-399.

Fischer HG, Reichmann G. 2001. Brain dendritic cells and macrophages/microglia in central nervous system inflammation. J Immunol 166: 2717-2726.

Ford AL, Goodsall AL, Hickey WF, Sedgwick JD. 1995. Normal adult ramified microglia separated from other central nervous system macrophages by flow cytometric sorting. Phenotypic differences defined and direct ex vivo antigen presentation to myelin basic protein-reactive $\mathrm{CD} 4^{+} \mathrm{T}$ cells compared. J Immunol 154: 4309-4321.

Foster CA, Howard LM, Schweitzer A, Persohn E, Hiestand PC, Balatoni B, Reuschel R, Beerli C, Schwartz M, Billich A. 2007. Brain penetration of the oral immunomodulato- ry drug FTY720 and its phosphorylation in the central nervous system during experimental autoimmune encephalomyelitis: Consequences for mode of action in multiple sclerosis. I Pharmacol Exp Therapeut 323: 469-475.

Frischer JM, Bramow S, Dal-Bianco A, Lucchinetti CF, Rauschka H, Schmidbauer M, Laursen H, Sorensen PS, Lassmann H. 2009. The relation between inflammation and neurodegeneration in multiple sclerosis brains. Brain 132: 1175-1189.

Fu R, Shen Q, Xu P, Luo JJ, Tang Y. 2014. Phagocytosis of microglia in the central nervous system diseases. Mol Neurobiol 49: 1422-1434.

Gao Z, Tsirka SE. 2011. Animal models of MS reveal multiple roles of microglia in disease pathogenesis. Neurol Res Int 2011: 383087.

Gehrmann J, Banati RB, Kreutzberg GW. 1993. Microglia in the immune surveillance of the brain: Human microglia constitutively express HLA-DR molecules. J Neuroimmunol 48: 189-198.

Gemma C, Bachstetter AD. 2013. The role of microglia in adult hippocampal neurogenesis. Front Cell Neurosci 7: 229.

Gerhauser I, Hansmann F, Puff C, Kumnok J, Schaudien D, Wewetzer K, Baumgartner W. 2012. Theiler's murine encephalomyelitis virus induced phenotype switch of microglia in vitro. J Neuroimmunol 252: 49-55.

Gkagkanasiou M, Ploussi A, Gazouli M, Efstathopoulos EP. 2016. USPIO-enhanced MRI neuroimaging: A review. J Neuroimaging 26: 161-168.

Goldmann T, Wieghofer P, Muller PF, Wolf Y, Varol D, Yona S, Brendecke SM, Kierdorf K, Staszewski O, Datta M, et al. 2013. A new type of microglia gene targeting shows TAK1 to be pivotal in CNS autoimmune inflammation. Nat Neurosci 16: 1618-1626.

Goldmann T, Zeller N, Raasch J, Kierdorf K, Frenzel K, Ketscher L, Basters A, Staszewski O, Brendecke SM, Spiess A, et al. 2015. USP18 lack in microglia causes destructive interferonopathy of the mouse brain. $E M B O J$ 34: 1612-1629.

Gonzalez H, Elgueta D, Montoya A, Pacheco R. 2014. Neuroimmune regulation of microglial activity involved in neuroinflammation and neurodegenerative diseases. $J$ Neuroimmunol 274: 1-13.

Goverman J. 2009. Autoimmune T cell responses in the central nervous system. Nat Rev Immunol 9: 393-407.

Graeber MB, Streit WJ, Buringer D, Sparks DL, Kreutzberg GW. 1992. Ultrastructural location of major histocompatibility complex (MHC) class II positive perivascular cells in histologically normal human brain. J Neuropathol Exp Neurol 51: 303-311.

Gray E, Thomas TL, Betmouni S, Scolding N, Love S. 2008a. Elevated activity and microglial expression of myeloperoxidase in demyelinated cerebral cortex in multiple sclerosis. Brain Pathol 18: 86-95.

Gray E, Thomas TL, Betmouni S, Scolding N, Love S. 2008b. Elevated myeloperoxidase activity in white matter in multiple sclerosis. Neurosci Lett 444: 195-198.

Greter M, Heppner FL, Lemos MP, Odermatt BM, Goebels N, Laufer T, Noelle RJ, Becher B. 2005. Dendritic cells 
E. O’Loughlin et al.

permit immune invasion of the CNS in an animal model of multiple sclerosis. Nat Med 11: 328-334.

Haider L, Fischer MT, Frischer JM, Bauer J, Hoftberger R, Botond G, Esterbauer H, Binder CJ, Witztum JL, Lassmann H. 2011. Oxidative damage in multiple sclerosis lesions. Brain 134: 1914-1924.

Haider L, Zrzavy T, Hametner S, Hoftberger R, Bagnato F, Grabner G, Trattnig S, Pfeifenbring S, Bruck W, Lassmann H. 2016. The topograpy of demyelination and neurodegeneration in the multiple sclerosis brain. Brain: $J$ Neurol 139: 807-815.

Hallgren B, Sourander P. 1958. The effect of age on the nonhaemin iron in the human brain. J Neurochem 3: 41-51.

Hametner S, Wimmer I, Haider L, Pfeifenbring S, Bruck W, Lassmann H. 2013. Iron and neurodegeneration in the multiple sclerosis brain. Ann Neurol 74: 848-861.

Hemmer B, Kerschensteiner M, Korn T. 2015. Role of the innate and adaptive immune responses in the course of multiple sclerosis. Lancet Neurol 14: 406-419.

Henderson AP, Barnett MH, Parratt JD, Prineas JW. 2009. Multiple sclerosis: Distribution of inflammatory cells in newly forming lesions. Ann Neurol 66: 739-753.

Heneka MT, Kummer MP, Latz E. 2014. Innate immune activation in neurodegenerative disease. Nat Rev Immunol 14: 463-477.

Heppner FL, Greter M, Marino D, Falsig J, Raivich G, Hovelmeyer N, Waisman A, Rulicke T, Prinz M, Priller J, et al. 2005. Experimental autoimmune encephalomyelitis repressed by microglial paralysis. Nat Med 11: 146-152.

Hickey WF, Kimura H. 1988. Perivascular microglial cells of the CNS are bone marrow-derived and present antigen in vivo. Science 239: 290-292.

Hickman SE, Kingery ND, Ohsumi TK, Borowsky ML, Wang LC, Means TK, El Khoury J. 2013. The microglial sensome revealed by direct RNA sequencing. Nat Neurosci 16: 1896-1905.

Hisahara S, Takano R, Shoji S, Okano H, Miura M. 2000. Role of caspase-1 subfamily in cytotoxic cytokine-induced oligodendrocyte cell death. I Neural Transm 2000: 135-142.

Hsieh CL, Koike M, Spusta SC, Niemi EC, Yenari M, Nakamura MC, Seaman WE. 2009. A role for TREM2 ligands in the phagocytosis of apoptotic neuronal cells by microglia. J Neurochem 109: 1144-1156.

Huitinga I, van Rooijen N, de Groot CJ, Uitdehaag BM Dijkstra CD. 1990. Suppression of experimental allergic encephalomyelitis in Lewis rats after elimination of macrophages. J Exp Med 172: 1025-1033.

Huitinga I, Damoiseaux JG, Dopp EA, Dijkstra CD. 1993. Treatment with anti-CR3 antibodies ED7 and ED8 suppresses experimental allergic encephalomyelitis in Lewis rats. Eur J Immunol 23: 709-715.

Huizinga R, van der Star BJ, Kipp M, Jong R, Gerritsen W, Clarner T, Puentes F, Dijkstra CD, van der Valk P, Amor S. 2012. Phagocytosis of neuronal debris by microglia is associated with neuronal damage in multiple sclerosis. Glia 60: 422-431.

Hunter SF, Bowen JD, Reder AT. 2016. The direct effects of fingolimod in the central nervous system: Implications for relapsing multiple sclerosis. CNS Drugs 30: 135-147.
Jack C, Ruffini F, Bar-Or A, Antel JP. 2005. Microglia and multiple sclerosis. J Neurosci Res 81: 363-373.

Kappos L, Antel J, Comi G, Montalban X, O’Connor P, Polman CH, Haas T, Korn AA, Karlsson G, Radue EW, et al. 2006. Oral fingolimod (FTY720) for relapsing multiple sclerosis. N Engl J Med 355: 1124-1140.

Kettenmann H, Hanisch UK, Noda M, Verkhratsky A. 2011 Physiology of microglia. Physiol Rev 91: 461-553.

Khorooshi R, Owens T. 2010. Injury-induced type I IFN signaling regulates inflammatory responses in the central nervous system. J Immunol 185: 1258-1264.

Kiferle L, Politis M, Muraro PA, Piccini P. 2011. Positron emission tomography imaging in multiple sclerosis-current status and future applications. Eur J Neurol 18: 226231.

Kirschbaum K, Sonner JK, Zeller MW, Deumelandt K, Bode J, Sharma R, Kruwel T, Fischer M, Hoffmann A, Costa da Silva $M$, et al. 2016. In vivo nanoparticle imaging of innate immune cells can serve as a marker of disease severity in a model of multiple sclerosis. Proc Natl Acad Sci 113: 13227-13232.

Kocur M, Schneider R, Pulm AK, Bauer J, Kropp S, Gliem M, Ingwersen J, Goebels N, Alferink J, Prozorovski T, et al. 2015. IFN $\beta$ secreted by microglia mediates clearance of myelin debris in CNS autoimmunity. Acta Neuropathol Commun 3: 20.

Krasemann S, Madore C, Cialic R, Baufeld C, Calcagno N, El Fatimy R, Beckers L, O'Loughlin E, Xu Y, Fanek Z, et al. 2017. The TREM2-APOE pathway drives the transcriptional phenotype of dysfunctional microglia in neurodegenerative diseases. Immunity 47: 566-581.e9.

Krichevsky AM, King KS, Donahue CP, Khrapko K, Kosik KS. 2003. A microRNA array reveals extensive regulation of microRNAs during brain development. RNA 9: 12741281.

Lampron A, Pimentel-Coelho PM, Rivest S. 2013. Migration of bone marrow-derived cells into the central nervous system in models of neurodegeneration. J Comp Neurol 521: 3863-3876.

Lassmann H. 2014. Mechanisms of white matter damage in multiple sclerosis. Glia 62: 1816-1830.

Lassmann H, Bradl M. 2017. Multiple sclerosis: Experimental models and reality. Acta Neuropathol 133: 223-244.

Lassmann H, Rossler K, Zimprich F, Vass K. 1991. Expression of adhesion molecules and histocompatibility antigens at the blood-brain barrier. Brain Pathol 1: 115-123.

Lassmann H, Schmied M, Vass K, Hickey WF. 1993. Bone marrow derived elements and resident microglia in brain inflammation. Glia 7: 19-24.

Lassmann H, Bruck W, Lucchinetti C. 2001. Heterogeneity of multiple sclerosis pathogenesis: Implications for diagnosis and therapy. Trends Mol Med 7: 115-121.

Lassmann H, Bruck W, Lucchinetti CF. 2007. The immunopathology of multiple sclerosis: An overview. Brain Pathol 17: 210-218.

Liddelow SA, Guttenplan KA, Clarke LE, Bennett FC, Bohlen CJ, Schirmer L, Bennett ML, Munch AE, Chung WS, Peterson TC, et al. 2017. Neurotoxic reactive astrocytes are induced by activated microglia. Nature 541: 481-487.

Liu GJ, Middleton RJ, Hatty CR, Kam WW, Chan R, Pham T, Harrison-Brown M, Dodson E, Veale K, Banati RB. 2014. 
The $18 \mathrm{kDa}$ translocator protein, microglia and neuroinflammation. Brain Pathol 24: 631-653.

Lopes KO, Sparks DL, Streit WJ. 2008. Microglial dystrophy in the aged and Alzheimer's disease brain is associated with ferritin immunoreactivity. Glia 56: 1048-1060.

Mack CL, Vanderlugt-Castaneda CL, Neville KL, Miller SD. 2003. Microglia are activated to become competent antigen presenting and effector cells in the inflammatory environment of the Theiler's virus model of multiple sclerosis. J Neuroimmunol 144: 68-79.

Mahad D, Ziabreva I, Lassmann H, Turnbull D. 2008. Mitochondrial defects in acute multiple sclerosis lesions. Brain 131: 1722-1735

Mahad DH, Trapp BD, Lassmann H. 2015. Pathological mechanisms in progressive multiple sclerosis. Lancet Neurol 14: 183-193.

Marik C, Felts PA, Bauer J, Lassmann H, Smith KJ. 2007. Lesion genesis in a subset of patients with multiple sclerosis: A role for innate immunity? Brain 130: 2800-2815.

Martinez FO, Gordon S. 2014. The M1 and M2 paradigm of macrophage activation: Time for reassessment. F1000Prime Rep 6: 13

Mayo L, Quintana FJ, Weiner HL. 2012. The innate immune system in demyelinating disease. Immunol Rev 248: 170187.

Mayo L, Cunha AP, Madi A, Beynon V, Yang Z, Alvarez JI, Prat A, Sobel RA, Kobzik L, Lassmann H, et al. 2016. IL10-dependent Tr1 cells attenuate astrocyte activation and ameliorate chronic central nervous system inflammation. Brain 139: 1939-1957.

McCarthy DP, Richards MH, Miller SD. 2012. Mouse models of multiple sclerosis: Experimental autoimmune encephalomyelitis and Theiler's virus-induced demyelinating disease. Methods Mol Biol 900: 381-401.

McMahon EJ, Bailey SL, Castenada CV, Waldner H, Miller SD. 2005. Epitope spreading initiates in the CNS in two mouse models of multiple sclerosis. Nat Med 11: 335339.

McQualter JL, Darwiche R, Ewing C, Onuki M, Kay TW, Hamilton JA, Reid HH, Bernard CC. 2001. Granulocyte macrophage colony-stimulating factor: A new putative therapeutic target in multiple sclerosis. J Exp Med 194: 873-882.

Metz LM, Li DKB, Traboulsee AL, Duquette P, Eliasziw M, Cerchiaro G, Greenfield J, Riddehough A, Yeung M, Kremenchutzky M, et al. 2017. Trial of minocycline in a clinically isolated syndrome of multiple sclerosis. $N$ Engl J Med 376: 2122-2133.

Mildner A, Mack M, Schmidt H, Bruck W, Djukic M, Zabel MD, Hille A, Priller J, Prinz M. 2009. CCR $2^{+}$Ly- $6 C^{\text {h }}$ monocytes are crucial for the effector phase of autoimmunity in the central nervous system. Brain 132: $2487-$ 2500.

Mildner A, Huang H, Radke J, Stenzel W, Priller J. 2017. P2Y12 receptor is expressed on human microglia under physiological conditions throughout development and is sensitive to neuroinflammatory diseases. Glia 65: $375-$ 387.

Miller SD, Karpus WJ. 2007. Experimental autoimmune encephalomyelitis in the mouse. Curr Protoc Immunol doi: 10.1002/0471142735.im1501s77.
Miranda-Hernandez S, Baxter AG. 2013. Role of Toll-like receptors in multiple sclerosis. Am J Clin Exp Immunol 2: 75-93.

Miron VE, Franklin RJ. 2014. Macrophages and CNS remyelination. J Neurochem 130: 165-171.

Miron VE, Jung CG, Kim HJ, Kennedy TE, Soliven B, Antel JP. 2008. FTY720 modulates human oligodendrocyte progenitor process extension and survival. Ann Neurol 63: 61-71.

Miron VE, Ludwin SK, Darlington PJ, Jarjour AA, Soliven B, Kennedy TE, Antel JP. 2010. Fingolimod (FTY720) enhances remyelination following demyelination of organotypic cerebellar slices. Am J Pathol 176: 2682-2694.

Mishra MK, Wang J, Keough MB, Fan Y, Silva C, Sloka S, Hayardeny L, Bruck W, Yong VW. 2014. Laquinimod reduces neuroaxonal injury through inhibiting microglial activation. Ann Clin Transl Neurol 1: 409-422.

Moore FG, Wolfson C. 2002. Human herpes virus 6 and multiple sclerosis. Acta Neurol Scand 106: 63-83.

Nagra RM, Becher B, Tourtellotte WW, Antel JP, Gold D, Paladino T, Smith RA, Nelson JR, Reynolds WF. 1997. Immunohistochemical and genetic evidence of myeloperoxidase involvement in multiple sclerosis. J Neuroimmunol 78: 97-107.

Napoli I, Neumann H. 2009. Microglial clearance function in health and disease. Neuroscience 158: 1030-1038.

Nau R, Bruck W. 2002. Neuronal injury in bacterial meningitis: Mechanisms and implications for therapy. Trends Neurosci 25: 38-45.

Nikic I, Merkler D, Sorbara C, Brinkoetter M, Kreutzfeldt M, Bareyre FM, Bruck W, Bishop D, Misgeld T, Kerschensteiner M. 2011. A reversible form of axon damage in experimental autoimmune encephalomyelitis and multiple sclerosis. Nat Med 17: 495-499.

Noda H, Takeuchi H, Mizuno T, Suzumura A. 2013. Fingolimod phosphate promotes the neuroprotective effects of microglia. J Neuroimmunol 256: 13-18.

Ohrfelt A, Axelsson M, Malmestrom C, Novakova L, Heslegrave A, Blennow K, Lycke J, Zetterberg H. 2016. Soluble TREM-2 in cerebrospinal fluid from patients with multiple sclerosis treated with natalizumab or mitoxantrone. Mult Scler 22: 1587-1595.

Oksenberg JR, Baranzini SE, Barcellos LF, Hauser SL. 2001. Multiple sclerosis: Genomic rewards. J Neuroimmunol 113: 171-184.

Peferoen L, Kipp M, van der Valk P, van Noort JM, Amor S. 2014. Oligodendrocyte-microglia cross-talk in the central nervous system. Immunology 141: 302-313.

Peferoen LA, Vogel DY, Ummenthum K, Breur M, Heijnen PD, Gerritsen WH, Peferoen-Baert RM, van der Valk P, Dijkstra CD, Amor S. 2015. Activation status of human microglia is dependent on lesion formation stage and remyelination in multiple sclerosis. J Neuropathol Exp Neurol 74: 48-63.

Perry VH, Holmes C. 2014. Microglial priming in neurodegenerative disease. Nat Rev Neurol 10: 217-224.

Pitt D, Boster A, Pei W, Wohleb E, Jasne A, Zachariah CR, Rammohan K, Knopp MV, Schmalbrock P. 2010. Imaging cortical lesions in multiple sclerosis with ultra-highfield magnetic resonance imaging. Arch Neurol 67: 812818. 
E. O’Loughlin et al.

Poliani PL, Wang Y, Fontana E, Robinette ML, Yamanishi Y Gilfillan S, Colonna M. 2015. TREM2 sustains microglial expansion during aging and response to demyelination. $J$ Clin Invest 125: 2161-2170.

Ponomarev ED, Shriver LP, Maresz K, Dittel BN. 2005. Microglial cell activation and proliferation precedes the onset of CNS autoimmunity. J Neurosci Res 81: 374-389.

Ponomarev ED, Veremeyko T, Barteneva N, Krichevsky AM, Weiner HL. 2011. microRNA-124 promotes microglia quiescence and suppresses EAE by deactivating macrophages via the C/EBP- $\alpha-$ PU.1 pathway. Nat Med 17: 64-70.

Popescu BF, Lucchinetti CF. 2012. Pathology of demyelinating diseases. Ann Rev Pathol 7: 185-217.

Popescu BF, Pirko I, Lucchinetti CF. 2013. Pathology of multiple sclerosis: Where do we stand? Continuum 19: 901921.

Praet J, Guglielmetti C, Berneman Z, Van der Linden A, Ponsaerts P. 2014. Cellular and molecular neuropathology of the cuprizone mouse model: Clinical relevance for multiple sclerosis. Neuroscie Biobehav Rev 47: 485-505.

Prinz M, Schmidt H, Mildner A, Knobeloch KP, Hanisch UK, Raasch J, Merkler D, Detje C, Gutcher I, Mages J, et al. 2008. Distinct and nonredundant in vivo functions of IFNAR on myeloid cells limit autoimmunity in the central nervous system. Immunity 28: 675-686.

Ransohoff RM. 2012. Animal models of multiple sclerosis: The good, the bad and the bottom line. Nat Neurosci 15 1074-1077.

Ransohoff RM. 2016. A polarizing question: Do M1 and M2 microglia exist? Nat Neurosci 19: 987-991.

Rice GI, Kasher PR, Forte GM, Mannion NM, Greenwood SM, Szynkiewicz M, Dickerson JE, Bhaskar SS, Zampini M, Briggs TA, et al. 2012. Mutations in ADAR1 cause Aicardi-Goutieres syndrome associated with a type I interferon signature. Nat Genet 44: 1243-1248.

Rinchai D, Boughorbel S, Presnell S, Quinn C, Chaussabel D. 2016. A curated compendium of monocyte transcriptome datasets of relevance to human monocyte immunobiology research. F1000Res 5: 291.

Rissanen E, Virta JR, Paavilainen T, Tuisku J, Helin S, Luoto P, Parkkola R, Rinne JO, Airas L. 2013. Adenosine A2A receptors in secondary progressive multiple sclerosis: A $\left[{ }^{11} \mathrm{C}\right]$ TMSX brain PET study. J Cereb Blood Flow Metab 33: 1394-1401.

Rissanen E, Tuisku J, Rokka J, Paavilainen T, Parkkola R, Rinne JO, Airas L. 2014. In vivo detection of diffuse inflammation in secondary progressive multiple sclerosis using PET imaging and the radioligand ${ }^{11} \mathrm{C}-\mathrm{PK} 11195 . J$ Nuclear Med 55: 939-944.

Sanders P, De Keyser J. 2007. Janus faces of microglia in multiple sclerosis. Brain Res Rev 54: 274-285.

Satoh J, Kino Y, Asahina N, Takitani M, Miyoshi J, Ishida T, Saito Y. 2016. TMEM119 marks a subset of microglia in the human brain. Neuropathology 36: 39-49.

Saxena A, Bauer J, Scheikl T, Zappulla J, Audebert M, Desbois S, Waisman A, Lassmann H, Liblau RS, Mars LT. 2008. Cutting edge: Multiple sclerosis-like lesions induced by effector CD8 T cells recognizing a sequestered antigen on oligodendrocytes. J Immunol 181: 1617-1621.
Schuh C, Wimmer I, Hametner S, Haider L, Van Dam AM, Liblau RS, Smith KJ, Probert L, Binder CJ, Bauer J, et al. 2014. Oxidative tissue injury in multiple sclerosis is only partly reflected in experimental disease models. Acta Neuropathol 128: 247-266.

Seong SY, Matzinger P. 2004. Hydrophobicity: An ancient damage-associated molecular pattern that initiates innate immune responses. Nat Rev Immunol 4: 469-478.

Shaked I, Porat Z, Gersner R, Kipnis J, Schwartz M. 2004. Early activation of microglia as antigen-presenting cells correlates with $\mathrm{T}$ cell-mediated protection and repair of the injured central nervous system. J Neuroimmunol 146: 84-93.

Singh S, Metz I, Amor S, van der Valk P, Stadelmann C, Bruck W. 2013. Microglial nodules in early multiple sclerosis white matter are associated with degenerating axons. Acta Neuropathol 125: 595-608.

Skaper SD, Facci L. 2012. Mast cell-glia axis in neuroinflammation and therapeutic potential of the anandamide congener palmitoylethanolamide. Philos Trans R Soc Lond B Biol Sci 367: 3312-3325.

Skaper SD, Facci L, Giusti P. 2014. Neuroinflammation, microglia and mast cells in the pathophysiology of neurocognitive disorders: A review. CNS Neurol Disord Drug Targets 13: 1654-1666.

Skripuletz T, Gudi V, Hackstette D, Stangel M. 2011. De- and remyelination in the CNS white and grey matter induced by cuprizone: The old, the new, and the unexpected. Histol Histopathol 26: 1585-1597.

Storch MK, Stefferl A, Brehm U, Weissert R, Wallstrom E, Kerschensteiner M, Olsson T, Linington C, Lassmann $\mathrm{H}$. 1998. Autoimmunity to myelin oligodendrocyte glycoprotein in rats mimics the spectrum of multiple sclerosis pathology. Brain Pathol 8: 681-694.

Swanborg RH, Whittum-Hudson JA, Hudson AP. 2003. Infectious agents and multiple sclerosis-Are Chlamydia pneumoniae and human herpes virus 6 involved? J Neuroimmunol 136: 1-8.

Symonds CP. 1975. Multiple sclerosis and the swayback story. Lancet 1: 155-156.

Takano A, Piehl F, Hillert J, Varrone A, Nag S, Gulyas B, Stenkrona P, Villemagne VL, Rowe CC, Macdonell R, et al. 2013. In vivo TSPO imaging in patients with multiple sclerosis: A brain PET study with $\left[{ }^{18} \mathrm{~F}\right]$ FEDAA1106. EJNMMI Res 3: 30.

Talbot PJ, Arnold D, Antel JP. 2001. Virus-induced autoimmune reactions in the CNS. Curr Top Microbiol Immunol 253: $247-271$.

Teige I, Treschow A, Teige A, Mattsson R, Navikas V, Leanderson T, Holmdahl R, Issazadeh-Navikas S. 2003. IFN- $\beta$ gene deletion leads to augmented and chronic demyelinating experimental autoimmune encephalomyelitis. $J$ Immunol 170: 4776-4784.

Tompkins SM, Padilla J, Dal Canto MC, Ting JP, Van Kaer L, Miller SD. 2002. De novo central nervous system processing of myelin antigen is required for the initiation of experimental autoimmune encephalomyelitis. JImmunol 168: 4173-4183.

Trapp BD, Peterson J, Ransohoff RM, Rudick R, Mork S, Bo L. 1998. Axonal transection in the lesions of multiple sclerosis. N Engl J Med 338: 278-285. 
Traugott NN, Zhirmunskaia EA. 1993. Physiologic changes in aminazine syndrome, traumatic shock and alimentary dystrophy. Fiziol Cheloveka 19: 174-176.

Traugott U, Reinherz EL, Raine CS. 1983. Multiple sclerosis. Distribution of T cells, $\mathrm{T}$ cell subsets and Ia-positive macrophages in lesions of different ages. J Neuroimmunol 4: 201-221.

Trudler D, Farfara D, Frenkel D. 2010. Toll-like receptors expression and signaling in glia cells in neuro-amyloidogenic diseases: Towards future therapeutic application. Mediators Inflamm doi: 10.1155/2010/497987.

Ulvestad E, Williams K, Vedeler C, Antel J, Nyland H, Mork S, Matre R. 1994. Reactive microglia in multiple sclerosis lesions have an increased expression of receptors for the Fc part of IgG. J Neurol Sci 121: 125-131.

van der Valk P, Amor S. 2009. Preactive lesions in multiple sclerosis. Curr Opin Neurol 22: 207-213.

Van Horssen J, Witte ME, Ciccarelli O. 2012. The role of mitochondria in axonal degeneration and tissue repair in MS. Mult Scler 18: 1058-1067.

Van Kooten C, Banchereau J. 2000. CD40-CD40 ligand. J Leukocyte Biol 67: 2-17.

Van Noort JM, van den Elsen PJ, van Horssen J, Geurts JJ, van der Valk P, Amor S. 2011. Preactive multiple sclerosis lesions offer novel clues for neuroprotective therapeutic strategies. CNS Neurol Disord Drug Targets 10: 68-81.

Vas A, Shchukin Y, Karrenbauer VD, Cselenyi Z, Kostulas K, Hillert J, Savic I, Takano A, Halldin C, Gulyas B. 2008. Functional neuroimaging in multiple sclerosis with radiolabelled glia markers: Preliminary comparative PET studies with $\left[{ }^{11} \mathrm{C}\right]$ vinpocetine and $\left[{ }^{11} \mathrm{C}\right] \mathrm{PK} 11195$ in patients. $J$ Neurol Sci 264: 9-17.

Vogel DY, Vereyken EJ, Glim JE, Heijnen PD, Moeton M, van der Valk P, Amor S, Teunissen CE, van Horssen J, Dijkstra CD. 2013. Macrophages in inflammatory multiple sclerosis lesions have an intermediate activation status. J Neuroinflamm 10: 35.

Wasser B, Pramanik G, Hess M, Klein M, Luessi F, Dornmair K, Bopp T, Zipp F, Witsch E. 2016. Increase of alternatively activated antigen presenting cells in active experimental autoimmune encephalomyelitis. J Neuroimmune Pharmacol 11: 721-732.

Webb M, Tham CS, Lin FF, Lariosa-Willingham K, Yu N, Hale J, Mandala S, Chun J, Rao TS. 2004. Sphingosine 1phosphate receptor agonists attenuate relapsing-remitting experimental autoimmune encephalitis in SJL mice. J Neuroimmunol 153: 108-121.
Wegner C, Stadelmann C, Pfortner R, Raymond E, Feigelson S, Alon R, Timan B, Hayardeny L, Bruck W. 2010. Laquinimod interferes with migratory capacity of $\mathrm{T}$ cells and reduces IL-17 levels, inflammatory demyelination and acute axonal damage in mice with experimental autoimmune encephalomyelitis. J Neuroimmunol 227: 133-143.

West AP, Shadel GS. 2017. Mitochondrial DNA in innate immune responses and inflammatory pathology. Nat Rev Immunol 17: 363-375.

Williams K, Ulvestad E, Waage A, Antel JP, McLaurin J. 1994. Activation of adult human derived microglia by myelin phagocytosis in vitro. J Neurosci Res 38: 433-443.

Windhagen A, Newcombe J, Dangond F, Strand C, Woodroofe MN, Cuzner ML, Hafler DA. 1995. Expression of costimulatory molecules B7-1 (CD80), B7-2 (CD86), and interleukin 12 cytokine in multiple sclerosis lesions. J Exp Med 182: 1985-1996.

Wlodarczyk A, Lobner M, Cedile O, Owens T. 2014. Comparison of microglia and infiltrating $\mathrm{CD} 11 \mathrm{c}^{+}$cells as antigen presenting cells for $\mathrm{T}$ cell proliferation and cytokine response. J Neuroinflamm 11: 57.

Wolfson C, Talbot P. 2002. Bacterial infection as a cause of multiple sclerosis. Lancet 360: 352-353.

Woodroofe MN, Bellamy AS, Feldmann M, Davison AN, Cuzner ML. 1986. Immunocytochemical characterisation of the immune reaction in the central nervous system in multiple sclerosis. Possible role for microglia in lesion growth. J Neurol Sci 74: 135-152.

Yamasaki R, Lu H, Butovsky O, Ohno N, Rietsch AM, Cialic R, Wu PM, Doykan CE, Lin J, Cotleur AC, et al. 2014. Differential roles of microglia and monocytes in the inflamed central nervous system. J Exp Med 211: 15331549.

Yang JS, Xu LY, Xiao BG, Hedlund G, Link H. 2004. Laquinimod (ABR-215062) suppresses the development of experimental autoimmune encephalomyelitis, modulates the Th1/Th2 balance and induces the Th3 cytokine TGF- $\beta$ in Lewis rats. J Neuroimmunol 156: 3-9.

Yiangou Y, Facer P, Durrenberger P, Chessell IP, Naylor A, Bountra C, Banati RR, Anand P. 2006. COX-2, CB2 and $\mathrm{P} 2 \mathrm{X} 7$-immunoreactivities are increased in activated microglial cells/macrophages of multiple sclerosis and amyotrophic lateral sclerosis spinal cord. BMC Neurol 6: 12.

Zrzavy T, Hametner S, Wimmer I, Butovsky O, Weiner HL, Lassmann H. 2017. Loss of "homeostatic" microglia and patterns of their activation in active multiple sclerosis. Brain 140: 1900-1913. 


\section{$\&_{\mathrm{CSH}}^{\infty} \&$ Cold Spring Harbor

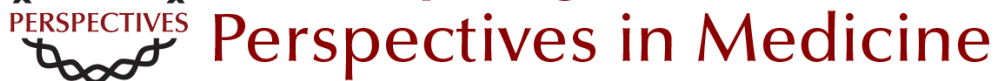

\section{Microglial Phenotypes and Functions in Multiple Sclerosis}

Elaine O'Loughlin, Charlotte Madore, Hans Lassmann and Oleg Butovsky

Cold Spring Harb Perspect Med 2018; doi: 10.1101/cshperspect.a028993

Subject Collection Multiple Sclerosis

Multiple Sclerosis Pathology

Hans Lassmann

Regulatory T Cells: From Discovery to

Autoimmunity

Alexandra Kitz, Emily Singer and David Hafler

The Multiple Roles of B Cells in Multiple Sclerosis and Their Implications in Multiple Sclerosis

Therapies

Rui Li and Amit Bar-Or

Autologous Hematopoietic Stem Cell

Transplantation in the Treatment of Multiple

Sclerosis

Carolina A. Rush, Harold L. Atkins and Mark S.

Freedman

B-Cell Therapies in Multiple Sclerosis Joseph J. Sabatino, Jr., Scott S. Zamvil and Stephen L. Hauser

Oral Therapies for Multiple Sclerosis Simon Faissner and Ralf Gold

Interferon $\beta$ for Multiple Sclerosis

Dejan Jakimovski, Channa Kolb, Murali

Ramanathan, et al.

Alemtuzumab as Treatment for Multiple Sclerosis Serafeim Katsavos and Alasdair Coles
Natalizumab: Perspectives from the Bench to

Bedside Afsaneh Shirani and Olaf Stüve

Daclizumab Therapy for Multiple Sclerosis Bibiana Bielekova

Lifestyle and Environmental Factors in Multiple Sclerosis Lars Alfredsson and Tomas Olsson

Biomarkers in Multiple Sclerosis Anu Paul, Manuel Comabella and Roopali Gandhi

The Evolving Mechanisms of Action of Glatiramer Acetate

Thomas Prod'homme and Scott S. Zamvil

Regulation of Astrocyte Functions in Multiple

Sclerosis

Michael A. Wheeler and Francisco J. Quintana

Experimental Autoimmune Encephalomyelitis

(EAE) as Animal Models of Multiple Sclerosis (MS) Simon Glatigny and Estelle Bettelli

Neurodegeneration in Progressive Multiple

Sclerosis

Graham Campbell and Don Mahad

For additional articles in this collection, see http://perspectivesinmedicine.cshlp.org/cgi/collection/ 